\title{
Cellular and molecular mechanisms involved in the neuroprotective effects of VEGF on motoneurons
}

\author{
Jerònia Lladón ${ }^{1,2}$ *, Laia Tolosa ${ }^{1,2 \dagger}$ and Gabriel Olmos ${ }^{1,2}$ \\ ' Grup de Neurobiologia Celular, Departament de Biologia, Universitat de les Illes Balears, Palma de Mallorca, Spain \\ ${ }_{2}^{2}$ Institut Universitari d'Investigacions en Ciències de la Salut (IUNICS), Universitat de les Illes Balears, Palma de Mallorca, Spain
}

\section{Edited by:}

Ricardo Tapia, Universidad Nacional Autónoma de México, Mexico

\section{Reviewed by:}

Angel M. Pastor, Universidad de Sevilla, Spain

Carmen Ruiz De Almodovar,

University of Heidelberg, Germany

\section{*Correspondence:}

Jerònia Lladó, Grup de Neurobiologia

Celular, Departament de Biologia,

Universitat de les IIles Balears, Ed.

Guillem Colom, Cra. de Valldemossa, $\mathrm{km}$ 7.5, E-07122 Palma de Mallorca,

Illes Balears, Spain

e-mail: jeronia.llado@uib.es

tPresent address:

Laia Tolosa, Unidad de Hepatología

Experimental, Instituto de

Investigación Sanitaria La Fe, Avda de

Campanar 21, E-46009 Valencia, Spain
Vascular endothelial growth factor (VEGF), originally described as a factor with a regulatory role in vascular growth and development, it is also known for its direct effects on neuronal cells. The discovery in the past decade that transgenic mice expressing reduced levels of VEGF developed late-onset motoneuron pathology, reminiscent of amyotrophic lateral sclerosis (ALS), opened a new field of research on this disease. VEGF has been shown to protect motoneurons from excitotoxic death, which is a relevant mechanism involved in motoneuron degeneration in ALS. Thus, VEGF delays motoneuron degeneration and increases survival in animal models of ALS. VEGF exerts its anti-excitotoxic effects on motoneurons through molecular mechanisms involving the VEGF receptor-2 resulting in the activation of the PI3-K/Akt signaling pathway, upregulation of GluR2 subunit of AMPA receptors, inhibition of p38MAPK, and induction of the anti-apoptotic molecule Bcl-2. In addition, VEGF acts on astrocytes to reduce astroglial activation and to induce the release of growth factors. The potential use of VEGF as a therapeutic tool in ALS is counteracted by its vascular effects and by its short effective time frame. More studies are needed to assess the optimal isoform, route of administration, and time frame for using VEGF in the treatment of ALS.

\section{Keywords: VEGF, motoneuron, ALS, AMPA receptors, excitotoxicity, Akt}

\section{INTRODUCTION}

Vascular endothelial growth factor (VEGF) was originally described as a factor with a regulatory role in vascular growth and development (reviewed by Carmeliet, 2003; Ferrara, 2004); currently, it is also known for its direct effects on a variety of neuronal cells, modulating neuronal migration, neuritic outgrowth, axon guidance and neuronal survival (reviewed by Ruiz de Almodovar et al., 2009; Mackenzie and Ruhrberg, 2012; Rosenstein et al., 2012).

The VEGFs form a family of growth factors that includes VEGF-A, VEGF-B, VEGF-C, VEGF-D, VEGF-E, and placental growth factor (Takahashi and Shibuya, 2005). The biological activity of the VEGF family is mediated through the binding to two classes of receptors. The tyrosine kinase receptors include the VEGF receptor-1 (VEGFR1, Flt-1), VEGF receptor-2 (VEGFR2, KDR, Flk-1), and VEGF receptor-3 (VEGFR3, Flt-4). The second class, the non-tyrosine kinase receptors, are the neuropilin1 (NP-1) and neuropilin-2 (NP-2), which are also receptors for semaphorins, and function as co-receptors for the VEGFRs (reviewed by Carmeliet and Ruiz de Almodovar, 2013).

Vascular endothelial growth factor-A (hereafter referred as VEGF) is expressed in different isoforms in humans, which differ in molecular mass, solubility, receptor affinity, and most likely, in its biological function. $V_{E G F} 165$ is the predominant isoform and is secreted as a $45-\mathrm{kDa}$ covalently linked homodimer (reviewed by Bogaert et al., 2006). VEGF is widely expressed throughout the central nervous system. Its expression has been reported in neurons (Ogunshola et al., 2002; Schiera et al., 2007), astroglia
(Ijichi et al., 1995), and microglia (Bartholdi et al., 1997). VEGF expression is low in the normal adult spinal cord (Fu et al., 2005); however, it increases in response to injury (Choi et al., 2007). VEGF binds to VEGFR1, VEGFR2, NP-1, and NP-2. VEGFR2 is expressed in many populations of neurons and some glial cells; whereas VEGFR1 is predominantly expressed by activated astrocytes and microglia following acute injury (Ogunshola et al., 2002; Choi et al., 2007; Krum et al., 2008; Ruiz de Almodovar et al., 2009). In addition, direct effects of VEGF on Schwann cells have been described (Sondell etal., 1999). NP-1 and NP2 are expressed in different types of neurons (Kolodkin etal., 1997; Giger etal., 1998), and also in spinal cord motoneurons (Oosthuyse et al., 2001).

Vascular endothelial growth factor has pro-survival effects on some neuronal cells, protects against experimentally induced cell death (Jin et al., 2000), stimulates axonal growth, and guidance (Sondell et al., 2000; Erskine et al., 2011; Ruiz de Almodovar et al., 2011), stimulates neurogenesis (Jin et al., 2002), regulates neuronal migration (Schwarz et al., 2004; Ruiz de Almodovar et al., 2010), and promotes dendrite patterning and synaptic plasticity (Licht et al., 2010, 2011). In addition to the vascular effects of VEGF protecting motoneurons by ensuring optimal blood supply to brain and spinal cord, it functions as a neurotrophic factor for motoneurons (Oosthuyse et al., 2001; Van Den Bosch et al., 2004). VEGF protects motoneurons from insults such as oxidative stress ( $\mathrm{Li}$ et al., 2003), hypoxia/hypoglycemia (Van Den Bosch et al., 2004), and glutamate-excitotoxicity (Tovar-Y-Romo et al., 2007; Tolosa et al., 2008; Tovar-Y-Romo and Tapia, 2010). 


\section{ROLE OF VEGF IN AMYOTROPHIC LATERAL SCLEROSIS PATHOGENESIS}

The discovery in the past decade that transgenic mice with a homozygous deletion in the hypoxia response element site in the VEGF promoter $\left(\mathrm{VEGF}^{\delta / \delta}\right.$ mice) expressed reduced levels of VEGF (25-40\% less) and developed late-onset motoneuron pathology reminiscent of amyotrophic lateral sclerosis (ALS), opened a new field of research on this dramatic disease. Interestingly, all the classic features of ALS including misaccumulation of neurofilaments in brainstem and spinal cord motoneurons, degeneration of motor axons, and denervation-induced muscle atrophy can be observed in these mice (Oosthuyse et al., 2001). As expected, mice engineered to overexpress VEGF had a delayed motoneuron degeneration and an increased survival when crossed to the superoxide dismutase-1 (SOD1) mouse model of ALS (Wang et al., 2007). In addition, the reduction in the levels of VEGF in the SOD1 mutant mice by crossbreeding the SOD1 mouse model of ALS with $\mathrm{VEGF}^{\delta / \delta}$ mice worsened the disease, resulting in a decrease in survival due to more severe motoneuron degeneration and earlier onset of muscle weakness (Lambrechts et al., 2003). Interestingly, in the SOD1 mutant mice model of ALS, mutant SOD1 can disrupt the post-transcriptional regulation of VEGF, leading to decreased production of this neurotrophic factor. This effect seems to be restricted to spinal cord, and the decline in VEGF mRNA levels is apparent before onset of weakness, and is more pronounced at middle and end-stages of the disease (Lu et al., 2007). Together, these results suggest a clear relationship between VEGF expression and the familial forms of ALS linked to SOD1 mutations. It still remains unknown the role that VEGF could play in sporadic ALS. In this sense, genetic studies in humans have indicated that VEGF is a modifier of motoneuron degeneration, as a low-VEGF genotype was associated to an increased susceptibility to ALS (Lambrechts et al., 2009).

It is accepted that the major mediator of the trophic effects on spinal cord motoneurons is VEGFR2 (Tolosa et al., 2008; Tovar-YRomo and Tapia, 2010), and the concurrent expression of VEGF and VEGFR2 may suggest autocrine/paracrine effects on these cells (Oosthuyse et al., 2001; Ogunshola et al., 2002; Brockington et al., 2006). Interestingly, both VEGF and VEGFR2 expression is reduced in motoneurons and spinal cord of ALS patients (Brockington etal., 2006). Furthermore, the importance of VEGFR2 has been reinforced by experiments showing increased survival of SOD1 mutant mice after overexpression of VEGFR2 (Storkebaum etal., 2005). These findings support the hypothesis that reduced VEGF signaling may play a role in the pathogenesis of ALS (reviewed by Sathasivam, 2008).

Excitotoxicity is a fundamental mechanism involved in motoneuron degeneration in ALS (reviewed by Van Den Bosch et al., 2006). Defective glutamate transport, causing an abnormally increased extracellular concentration of glutamate and over activation of glutamate receptors, has been proposed as an important mechanism in the excitotoxic process in ALS (Rothstein, 2009). In this regard, a decreased expression of the GLT-1 astroglial transporter has been found in the SOD1 animal models around spinal cord motoneurons (Bendotti etal., 2001; Howland etal., 2002). Excessive calcium influx through $\alpha$-amino-3-hydroxy-5-methyl-4-isoxazole propionic acid
(AMPA) glutamate receptors is the final effector of motoneuron death in the excitotoxic process. Motoneurons are especially vulnerable to AMPA receptor-mediated excitotoxicity both in vitro and in vivo as they express a high number of $\mathrm{Ca}^{2+}$-permeable AMPA receptors (Carriedo etal., 1996; Van Den Bosch etal., 2000). The permeability of the AMPA receptor depends upon the GluR2 subunit, which regulates the permeability to calcium: only AMPA receptors lacking GluR2 are permeable to calcium. In this regard, motoneurons express low levels of GluR2 and this renders them vulnerable to AMPA receptor-mediated excitotoxicity (Van Damme et al., 2002). Thus, selective loss of motoneurons can be induced experimentally by intrathecal or intraspinal administration of AMPA receptor agonists (Corona and Tapia, 2004; Sun et al., 2006).

In our laboratory, we used spinal cord organotypic cultures to create a model of chronic glutamate excitotoxicity in which glutamate transporters were inhibited by threohydroxyaspartate (THA) to induce motoneuron death. The exposure of these cultures to THA in the presence of VEGF significantly increased motoneuron survival (Tolosa et al., 2008). Similar results were previously obtained in vivo after AMPA-induced chronic excitotoxicity in rat spinal cord (Tovar-Y-Romo et al., 2007). Thus, VEGF protects motoneurons from excitotoxic death; however, it has been recently demonstrated in vivo that the therapeutic potential of VEGF against excitotoxicity has a short effective time frame, i.e., VEGF was effective only when administered before the onset of motor symptoms (Tovar-y-Romo and Tapia, 2012).

\section{MECHANISMS OF VEGF PROTECTION AGAINST EXCITOTOXICITY IN ALS}

Matsuzaki et al. (2001) initially identified VEGFR2 as the receptor responsible for the neuroprotective effects of VEGF against excitotoxicity in hippocampal neurons. VEGFR2 is expressed by motoneurons in humans (Brockington et al., 2006), mouse (Oosthuyse et al., 2001), and neonatal (Tolosa et al., 2008) and adult rats (Tovar-Y-Romo and Tapia, 2010), and the antiexcitotoxic effects of VEGF in these cells have also been attributed to this receptor (Bogaert et al., 2006; Tolosa et al., 2008; Tovar-YRomo and Tapia, 2010).

The signal transduction pathways activated by VEGF are wellcharacterized in endothelial cells; however, the knowledge of the signaling pathways involved in the anti-excitotoxic effects of VEGF is still incomplete. Upon ligand binding, VEGFR2 undergoes phosphorylation (Meyer et al., 1999), activating intracellular signaling pathways including phosphatidylinositol 3-kinase (PI3$\mathrm{K}) /$ Akt and mitogen-activated protein kinase/extracellular signalregulated kinase (MEK)/extracellular signal-regulated kinase (ERK). The relevance of the PI3-K/Akt pathway in the neuroprotective effects of VEGF was first proven on the motoneuron-like NSC34 cell line (Li etal., 2003) and also in SOD1 mutant rats where it was shown to counteract the loss of Akt activity preceding motoneuron degeneration (Dewil et al., 2007b). We demonstrated for the first time in spinal cord organotypic cultures that inhibition of the PI3-K/Akt pathway abolishes the anti-excitotoxic effects of VEGF on motoneurons exposed to a glutamate transporter inhibitor (Tolosa et al., 2008). These results were further confirmed in vivo in rats exposed to AMPA (Tovar-Y-Romo and 
Tapia, 2010). These studies also suggested that the MEK/ERK was less relevant than the PI3-K/Akt signaling pathway, as MEK inhibition had a limited effect on the VEGF-mediated neuroprotection against AMPA-induced excitotoxicity (Tovar-Y-Romo and Tapia, 2010).

Activation of PI3-K by VEGF has additional neuroprotective implications as Akt phosphorylates and activates the cyclic AMP-response element binding protein (CREB), involved in the transcription of the Bcl-2 gene (Pugazhenthi et al., 2000). We demonstrated that excitotoxic conditions are associated to a decreased expression of Bcl-2 in spinal cord cultures, and that VEGF-induced neuroprotection in motoneurons could be related to the restoration, via PI3-K, of Bcl-2 levels in these cultures, and specifically in motoneurons (Tolosa et al., 2008). Bcl-2, besides its ability to block cytochrome $c$ release, has been shown to increase calcium uptake and buffering capacity in mitochondria (Zhong et al., 1993), thus protecting against excitotoxicity. Additionally, it has been shown that Bcl-2 overexpression attenuates motoneuron degeneration in the SOD1 animal model (Azzouz et al., 2000).

Interestingly, it has been suggested that the PI3-K/Akt signaling pathway could be involved in GluR2 subunit assembly into AMPA receptors (Rainey-Smith et al., 2010). In this sense, VEGF has been shown, both in vitro and in vivo, to increase the expression of GluR2 subunit, thus reducing the permeability of AMPA receptors to calcium, and minimizing the vulnerability of motoneurons to AMPA-mediated excitotoxicity (Bogaert et al., 2010). Thus, a potential mechanism for VEGF protection against excitotoxicity would be through a PI3-K/Akt-mediated insertion of the GluR2 subunit of the AMPA receptor in motoneurons. Astrocytes are able to protect against excitotoxicity by inducing GluR2 expression in motoneurons. Interestingly, mutant SOD1 abolishes the ability of astrocytes to regulate GluR2 and thus, increase the susceptibility of motoneurons to excitotoxicity (Van Damme et al., 2007). It remains unknown if the VEGF-induced insertion of GluR2 could be astrocyte-mediated.

p38 mitogen-activated protein kinase (p38MAPK) belongs to a family of protein kinases activated by a range of stimuli including proinflammatory cytokines and oxidative stress (Mielke and Herdegen, 2000). As increased phosphorylation of p38MAPK has been reported in the spinal cord of SOD1 mutant mice, in motoneurons and glial cells, this kinase has been suggested to play a role in the pathogenesis of ALS (Tortarolo et al., 2003; Bendotti et al., 2004). In addition, a motoneuron specific death pathway, involving Fas, p38MAPK, and neuronal nitric oxide synthase activation has been described. Motoneurons from SOD1 mutant mice displayed increased susceptibility to activation of this pathway (Raoul et al., 2002).

Rho-mediated calcium-dependent activation of p38 $\alpha$ MAPK has been described as a trigger of excitotoxic cell-death (Semenova et al., 2007). In this regard, it has been shown that VEGF is able to block the AMPA-induced phosphorylation of p38MAPK (Tovar-Y-Romo and Tapia, 2010), thus identifying another molecular mechanism for the anti-excitotoxic effects of VEGF. However, the sole inhibition of p38MAPK activity is not sufficient to protect motoneurons against excitotoxicity as the anti-excitotoxic effects of VEGF are also dependent on the activation of the
PI3-K/Akt pathway (Tovar-Y-Romo and Tapia, 2010). In this regard, PI3-K/Akt has been reported to inhibit the phosphorylation of p38MAPK in an apoptosis signal-regulating kinase 1 (ASK1)-dependent manner (Ichijo et al., 1997; Kim et al., 2001). In agreement with that, our group has demonstrated that VEGF protects motoneurons from serum deprivation-induced cell death through PI3-K-mediated inhibition of p38MAPK phosphorylation (Tolosa et al., 2009). Moreover, the inhibition by VEGF of p38MAPK might protect motoneurons in ALS tissue exerting a dual role both through an indirect effect on glial cells (Tortarolo et al., 2003), and a direct anti-apoptotic effect on motoneurons (Dewil et al., 2007a).

\section{ROLE OF NON-NEURONAL CELLS IN THE NEUROPROTECTIVE EFFECTS OF VEGF}

Astroglia (Oosthuyse et al., 2001) and microglia (Bartholdi et al., 1997) are sources of VEGF in the spinal cord and a role for nonneuronal cells has been described in the onset and progression of the pathology in ALS (Clement et al., 2003; Barbeito et al., 2004; Sargsyan et al., 2005). It has been hypothesized that VEGF may also affect motoneurons through an indirect effect on glial cells, as both astrocytes (Krum et al., 2002) and microglia (Ryu et al., 2009) respond to VEGF stimulation. On the one hand, VEGF may affect the glial release of trophic factors, and thus, indirectly, protect motoneurons (reviewed by Bogaert et al., 2006). On the other hand, VEGF decreases the astroglial activation observed in the SOD1 mouse model of ALS, and also enhances neuromuscular junction formation (Zheng et al., 2007). Moreover, the neuroprotective effects observed with lithium in animal models of ALS could be due, in part, to an upregulation of VEGF in nonneuronal cells, as an increase in VEGF has been observed after lithium exposure in brain astrocytes and endothelial cells (Guo et al., 2009). In spite of these potential neuroprotective effects of VEGF involving non-neuronal cells, recently, it has been demonstrated that, under inflammatory conditions, astrocytic expression of VEGF is a key driver of blood-brain barrier disruption, leading to edema, excitotoxicity, and entry of inflammatory cells (Argaw et al., 2012).

Several in vivo and in vitro studies have indicated that VEGF induces adult neurogenesis (Jin et al., 2002; Cao et al., 2004). It still remains unknown if VEGF in vivo induces neurogenesis directly in neural stem cells or indirectly through effects on endothelial cells or other cell types (reviewed by Carmeliet and Ruiz de Almodovar, 2013). The potential of VEGF generating new neurons, together with its ability to induce axon growth could be relevant in its neuroprotective effects on ALS.

\section{POTENTIAL USE OF VEGF AS A THERAPEUTIC TOOL IN ALS}

Vascular endothelial growth factor clearly ameliorates the illness in the mutant SOD1 mice and rats (Azzouz et al., 2004; Storkebaum et al., 2005; Wang et al., 2007), supporting the hypothesis of a role for VEGF in ALS. VEGF has been administered to animals using different strategies. VEGF was administered using lentiviral vectors (intramuscularly delivered and then retrogradely transported) increasing the life expectancy of ALS mice. The treatment was more effective when initiated before disease onset (Azzouz et al., 2004). 


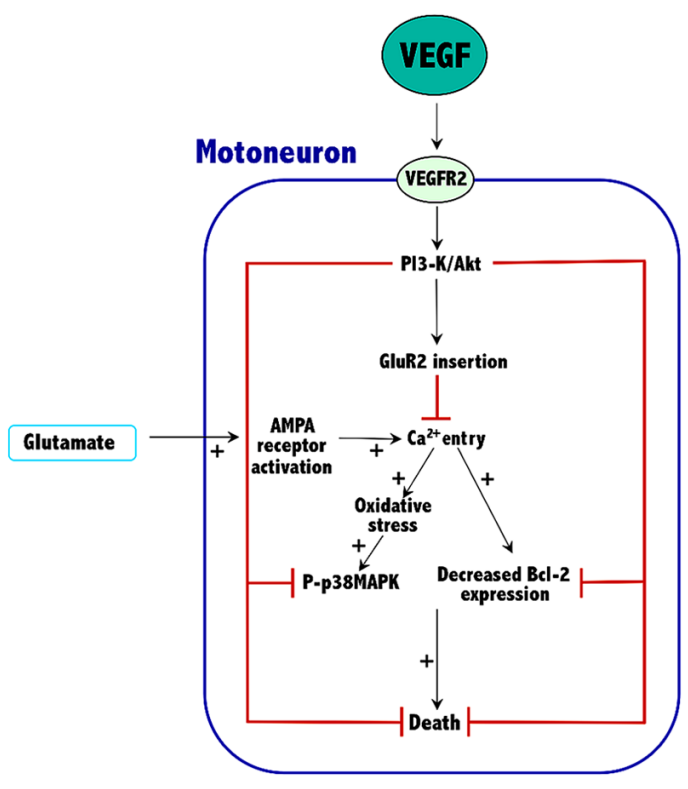

FIGURE 1 | Mechanisms involved in the neuroprotective effects of VEGF against excitotoxicity in spinal cord motoneurons. The plus symbols $(+)$ indicate the signaling pathways that are potentiated by excitotoxicity. See Section "Conclusion" for further details.

Intravenous administration of VEGF induces vascular effects: blood vessel growth or blood-brain barrier alterations (Young et al., 2004). To avoid these problematic side-effects, continuous intracerebroventricular (i.c.v.) administration of VEGF in ALS rats was performed. VEGF at doses between 0.2 and $2 \mu \mathrm{g} \cdot \mathrm{kg}^{-1}$. day was safe as it did not induce angiogenesis or inflammation. Besides, it was demonstrated that VEGF diffused from the cerebrospinal fluid to the spinal cord parenchyma, reaching motoneurons, and thus, improving motor performance and prolonging survival of SOD1 rats (Storkebaum et al., 2005). Thus, either retrograde (Azzouz et al., 2004) or paracrine (Storkebaum et al., 2005) delivery of VEGF is effective in the animal models of ALS.

Poesen etal. (2008) have demonstrated that the VEGF-B 186 isoform is also expressed in the nervous system, has less vascular effects, and also functions as a neuroprotective factor for motoneurons. Interestingly, in contrast to VEGF-A, the presence of VEGF-B is not critical for survival or for motoneuron

\section{REFERENCES}

Argaw, A. T., Asp, L., Zhang, J., Navrazhina, K., Pham, T., Mariani, J. N., et al. (2012). Astrocyte-derived VEGF-A drives blood-brain barrier disruption in CNS inflammatory disease. J. Clin. Invest. 122, 2454-2468. doi: 10.1172/JCI60842

Azzouz, M., Hottinger, A., Paterna, J. C., Zurn, A. D., Aebischer, P., and Bueler, H. (2000). Increased motoneuron survival and improved neuromuscular function in transgenic ALS mice after intraspinal injection of an adeno-associated virus encoding
Bcl-2. Hum. Mol. Genet. 9, 803-811. doi: 10.1093/hmg/9.5.803

Azzouz, M., Ralph, G. S., Storkebaum, E., Walmsley, L. E., Mitrophanous, K. A., Kingsman, S. M., et al. (2004). VEGF delivery with retrogradely transported lentivector prolongs survival in a mouse ALS model. Nature 429, 413-417. doi: 10.1038/nature02544

Barbeito, L. H., Pehar, M., Cassina, P., Vargas, M. R., Peluffo, H., Viera, L., et al. (2004). A role for astrocytes in motor neuron loss in amyotrophic lateral sclerosis. Brain Res.

development in physiological conditions; however, crossing VEGF-B $^{-/-}$mice with SOD1 mice aggravated motoneuron degeneration. The effect of VEGF- $\mathrm{B}_{186}$ seems to be mediated by VEGFR-1, which is also expressed by spinal cord motoneurons, indicating that they can respond to this VEGF-B isoform. In addition, as VEGFR1 is also expressed on astrocytes, an indirect effect on glia could not be ruled out. Finally, the authors demonstrated that i.c.v. delivery of VEGF-B ameliorated the disease in SOD1 rats without exhibiting side vascular effects (Poesen et al., 2008).

Taking advantage of these previous studies on animal models of ALS, ongoing clinical trials are essaying direct i.c.v. administration of VEGF in humans. Clinical trials on phase I/II investigate safety parameters in ALS patients and those on phase II/III are intended to evaluate the efficacy to increase lifespan (http://www.neuronova.com/index.php?option=com_content\& task=view\&id=40\&Itemid=71).

\section{CONCLUSION}

Current knowledge indicates that VEGF can prevent excitotoxic motoneuron death, thus prolonging survival in an animal model of ALS. These effects are VEGFR2-mediated and involve the activation of the PI3-K/Akt signaling pathway, which results in an increased expression of both $\mathrm{Bcl}-2$ and the GluR2 subunit of AMPA receptors. The overall effect of these proteins would be to reduce the excessive entry of calcium characteristic of the excitotoxic process. Thus, Bcl-2 increases the calcium uptake and the buffering capacity of mitochondria, and GluR2 assembly into AMPA receptors reduces their permeability to calcium. By reducing calcium levels into motoneurons of ALS tissue, VEGF reduces oxidative stress and p38MAPK activity, thus improving survival (Figure 1).

Although many of the experimental evidences of the benefits of VEGF in ALS are taken from in vitro or ex vivo experiments, the promising results obtained in animal models of familial ALS substantiate a potential use of VEGF as a therapeutic tool. However, its effectiveness may be counteracted by its vascular effects and by its expected short effective time frame (Tovar-y-Romo and Tapia, 2012). Clearly, more studies are needed to assess the optimal family member/isoform, the route of administration and the time frame for using VEGF in the treatment of ALS. In addition, a better understanding of the cellular and molecular mechanisms involved in the neuroprotective effects of VEGF will be crucial for its therapeutic development.

Brain Res. Rev. 47, 263-274. doi: 10.1016/j.brainresrev.2004.05.003

Bartholdi, D., Rubin, B. P., and Schwab, M. E. (1997). VEGF mRNA induction correlates with changes in the vascular architecture upon spinal cord damage in the rat. Eur. J. Neurosci. 9, 2549-2560. doi: 10.1111/j.14609568.1997.tb01684.x

Bendotti, C., Atzori, C., Piva, R., Tortarolo, M., Strong, M. J., Debiasi, S., etal. (2004). Activated p38MAPK is a novel component of the intracellular inclusions found in human amyotrophic lateral sclerosis and mutant SOD1 transgenic mice. J. Neuropathol. Exp. Neurol. 63, 113119.

Bendotti, C., Tortarolo, M., Suchak, S. K., Calvaresi, N., Carvelli, L., Bastone, A., et al. (2001). Transgenic SOD1 G93A mice develop reduced GLT1 in spinal cord without alterations in cerebrospinal fluid glutamate levels. J. Neurochem. 79, 737-746. doi: 10.1046/j.1471-4159.2001.00572.x

Bogaert, E., Van Damme, P., Poesen, K., Dhondt, J., Hersmus, N., Kiraly, D., etal. (2010). VEGF protects motor neurons against excitotoxicity 
by upregulation of GluR2. Neurobiol. Aging 31, 2185-2191. doi: 10.1016/j.neurobiolaging.2008.12.007

Bogaert, E., Van Damme, P., Van Den Bosch, L., and Robberecht, W. (2006). Vascular endothelial growth factor in amyotrophic lateral sclerosis and other neurodegenerative diseases. Muscle Nerve 34, 391-405. doi: 10.1002/mus.20609

Brockington, A., Wharton, S. B., Fernando, M., Gelsthorpe, C. H., Baxter, L., Ince, P. G., et al. (2006). Expression of vascular endothelial growth factor and its receptors in the central nervous system in amyotrophic lateral sclerosis. J. $\mathrm{Neu}$ ropathol. Exp. Neurol. 65, 26-36. doi: 10.1097/01.jnen.0000196134.51 217.74

Cao, L., Jiao, X., Zuzga, D. S., Liu, Y., Fong, D. M., Young, D., et al. (2004). VEGF links hippocampal activity with neurogenesis, learning and memory. Nat. Genet. 36, 827835. doi: $10.1038 / n g 1395$

Carmeliet, P. (2003). Angiogenesis in health and disease. Nat. Med. 9, 653-660. doi: 10.1038/nm0603-653

Carmeliet, P., and Ruiz de Almodovar, C. (2013). VEGF ligands and receptors: implications in neurodevelopment and neurodegeneration. Cell. Mol. Life Sci. 70, 1763-1778. doi: 10.1007/s00018-013-1283-7

Carriedo, S. G., Yin, H. Z., and Weiss, J. H. (1996). Motor neurons are selectively vulnerable to AMPA/kainate receptor-mediated injury in vitro. $J$. Neurosci. 16, 4069-4079.

Choi, J. S., Kim, H. Y., Cha, J. H., Choi, J. Y., Park, S. I., Jeong, C. H., et al. (2007). Upregulation of vascular endothelial growth factor receptors Flt-1 and Flk-1 following acute spinal cord contusion in rats. J. Histochem. Cytochem. 55, 821-830. doi: 10.1369/jhc.6A7139.2007

Clement, A. M., Nguyen, M. D., Roberts, E. A., Garcia, M. L., Boillee, S., Rule, M., et al. (2003). Wild-type nonneuronal cells extend survival of SOD1 mutant motor neurons in ALS mice. Science 302, 113-117. doi: 10.1126/science. 1086071

Corona, J. C., and Tapia, R. (2004). AMPA receptor activation, but not the accumulation of endogenous extracellular glutamate, induces paralysis and motor neuron death in rat spinal cord in vivo. J. Neurochem. 89, 988-997. doi: 10.1111/j.14714159.2004.02383.x

Dewil, M., Dela Cruz, V. F., Van Den Bosch, L., and Robberecht, W. (2007a). Inhibition of p38 mitogen activated protein kinase activation and mutant SOD1(G93A)- induced motor neuron death. Neurobiol. Dis. 26, 332-341. doi: 10.1016/j.nbd.2006.12.023

Dewil, M., Lambrechts, D., Sciot, R., Shaw, P. J., Ince, P. G., Robberecht, W., et al. (2007b). Vascular endothelial growth factor counteracts the loss of phospho-Akt preceding motor neurone degeneration in amyotrophic lateral sclerosis. $\mathrm{Neu}$ ropathol. Appl. Neurobiol. 33, 499509. doi: 10.1111/j.1365-2990.2007. 00850.x

Erskine, L., Reijntjes, S., Pratt, T., Denti, L., Schwarz, Q., Vieira, J. M., et al. (2011). VEGF signaling through neuropilin 1 guides commissural axon crossing at the optic chiasm. Neuron 70, 951-965. doi: 10.1016/j.neuron.2011.02.052

Ferrara, N. (2004). Vascular endothelial growth factor: basic science and clinical progress. Endocr. Rev. 25, 581-611. doi: 10.1210/er.2003-0027

$\mathrm{Fu}$, C. Y., Hong, G. X., and Wang, F. B. (2005). Expression of vascular endothelial growth factor and its fetal liver kinase-1 receptor in spinal cord and dorsal root ganglia after neurotomy of sciatic nerve in rats. Chin. J. Traumatol. 8, 17-22.

Giger, R. J., Urquhart, E. R., Gillespie, S. K., Levengood, D. V., Ginty, D. D., and Kolodkin, A. L. (1998). Neuropilin-2 is a receptor for semaphorin IV: insight into the structural basis of receptor function and specificity. Neuron 21, 10791092. doi: 10.1016/S0896-6273(00) 80625-X

Guo, S., Arai, K., Stins, M. F., Chuang, D. M., and Lo, E. H. (2009). Lithium upregulates vascular endothelial growth factor in brain endothelial cells and astrocytes. Stroke 40, 652-655. doi: 10.1161/STROKEAHA.108.524504

Howland, D. S., Liu, J., She, Y., Goad, B., Maragakis, N. J., Kim, B., et al. (2002). Focal loss of the glutamate transporter EAAT2 in a transgenic rat model of SOD1 mutant-mediated amyotrophic lateral sclerosis (ALS). Proc. Natl. Acad. Sci. U.S.A. 99, 16041609. doi: 10.1073/pnas.032539299

Ichijo, H., Nishida, E., Irie, K., Ten Dijke, P., Saitoh, M., Moriguchi, T., et al. (1997). Induction of apoptosis by ASK1, a mammalian MAPKKK that activates SAPK/JNK and p38 signaling pathways. Science 275, 90-94. doi: 10.1126/science.275.5296.90

Ijichi, A., Sakuma, S., and Tofilon, P. J. (1995). Hypoxia-induced vascular endothelial growth factor expression in normal rat astrocyte cultures. Glia 14, 87-93. doi: 10.1002/glia.440140203
Jin, K., Zhu, Y., Sun, Y., Mao, X. O., Xie, L., and Greenberg, D. A. (2002). Vascular endothelial growth factor (VEGF) stimulates neurogenesis in vitro and in vivo. Proc. Natl. Acad. Sci. U.S.A. 99, 11946-11950. doi: 10.1073/pnas.182296499

Jin, K. L., Mao, X. O., and Greenberg, D. A. (2000). Vascular endothelial growth factor: direct neuroprotective effect in in vitro ischemia. Proc. Natl. Acad. Sci. U.S.A. 97, 10242-10247. doi: 10.1073/pnas.97.18.10242

Kim, A. H., Khursigara, G., Sun, X., Franke, T. F., and Chao, M. V. (2001). Akt phosphorylates and negatively regulates apoptosis signal-regulating kinase 1. Mol. Cell. Biol. 21, 893901. doi: 10.1128/MCB.21.3.893901.2001

Kolodkin, A. L., Levengood, D. V., Rowe, E. G., Tai, Y. T., Giger, R. J., and Ginty, D. D. (1997). Neuropilin is a semaphorin III receptor. Cell 90, 753-762. doi: 10.1016/S00928674(00)80535-8

Krum, J. M., Mani, N., and Rosenstein, J. M. (2002). Angiogenic and astroglial responses to vascular endothelial growth factor administration in adult rat brain. Neuroscience 110, 589604. doi: 10.1016/S0306-4522(01) 00615-7

Krum, J. M., Mani, N., and Rosenstein, J. M. (2008). Roles of the endogenous VEGF receptors flt-1 and flk-1 in astroglial and vascular remodeling after brain injury. Exp. Neurol. 212, 108-117. doi: 10.1016/j.expneurol.2008.03.019

Lambrechts, D., Poesen, K., FernandezSantiago, R., Al-Chalabi, A., Del Bo, R., Van Vught, P. W., et al. (2009). Meta-analysis of vascular endothelial growth factor variations in amyotrophic lateral sclerosis: increased susceptibility in male carriers of the -2578AA genotype. J. Med. Genet. 46, 840-846. doi: 10.1136/jmg.2008.058222

Lambrechts, D., Storkebaum, E., Morimoto, M., Del-Favero, J., Desmet, F., Marklund, S. L., et al. (2003). VEGF is a modifier of amyotrophic lateral sclerosis in mice and humans and protects motoneurons against ischemic death. Nat. Genet. 34, 383 394. doi: 10.1038/ng1211

Li, B., Xu, W., Luo, C., Gozal, D., and Liu, R. (2003). VEGF-induced activation of the PI3-K/Akt pathway reduces mutant SOD1-mediated motor neuron cell death. Brain Res. Mol. Brain Res. 111, 155164. doi: 10.1016/S0169-328X(03) 00025-1

Licht, T., Eavri, R., Goshen, I., Shlomai, Y., Mizrahi, A., and Keshet,
E. (2010). VEGF is required for dendritogenesis of newly born olfactory bulb interneurons. Development 137, 261-271. doi: 10.1242/dev. 039636

Licht, T., Goshen, I., Avital, A., Kreisel, T., Zubedat, S., Eavri, R., et al. (2011). Reversible modulations of neuronal plasticity by VEGF. Proc. Natl. Acad. Sci. U.S.A. 108, 5081-5086. doi: 10.1073/pnas. 1007640108

Lu, L., Zheng, L., Viera, L., Suswam, E., Li, Y., Li, X., et al. (2007). Mutant $\mathrm{Cu} / \mathrm{Zn}$-superoxide dismutase associated with amyotrophic lateral sclerosis destabilizes vascular endothelial growth factor mRNA and downregulates its expression. J. Neurosci. 27, 7929-7938. doi: 10.1523/JNEUROSCI.1877-07.2007

Mackenzie, F., and Ruhrberg, C. (2012). Diverse roles for VEGF-A in the nervous system. Development 139, 13711380. doi: 10.1242/dev.072348

Matsuzaki, H., Tamatani, M., Yamaguchi, A., Namikawa, K., Kiyama, H., Vitek, M. P., et al. (2001). Vascular endothelial growth factor rescues hippocampal neurons from glutamate-induced toxicity: signal transduction cascades. FASEB J. 15, 1218-1220.

Meyer, M., Clauss, M., LeppleWienhues, A., Waltenberger, J., Augustin, H. G., Ziche, M., et al. (1999). A novel vascular endothelial growth factor encoded by Orf virus, VEGF-E, mediates angiogenesis via signalling through VEGFR-2 (KDR) but not VEGFR-1 (Flt-1) receptor tyrosine kinases. EMBO J. 18, 363374. doi: 10.1093/emboj/18.2.363

Mielke, K., and Herdegen, T. (2000). JNK and p38 stresskinases - degenerative effectors of signal-transductioncascades in the nervous system. Prog. Neurobiol. 61, 45-60. doi: 10.1016/S0301-0082(99)00042-8

Ogunshola, O. O., Antic, A., Donoghue, M. J., Fan, S. Y., Kim, H., Stewart, W. B., et al. (2002). Paracrine and autocrine functions of neuronal vascular endothelial growth factor (VEGF) in the central nervous system. J. Biol. Chem. 277, 11410-11415. doi: 10.1074/jbc.M111085200

Oosthuyse, B., Moons, L., Storkebaum, E., Beck, H., Nuyens, D., Brusselmans, K., et al. (2001). Deletion of the hypoxia-response element in the vascular endothelial growth factor promoter causes motor neuron degeneration. Nat. Genet. 28, 131138. doi: 10.1038/88842

Poesen, K., Lambrechts, D., Van Damme, P., Dhondt, J., Bender, F., Frank, N., et al. (2008). Novel role for vascular endothelial growth factor 
(VEGF) receptor-1 and its ligand VEGF-B in motor neuron degeneration. J. Neurosci. 28, 10451-10459. doi: 10.1523/JNEUROSCI.1092-08. 2008

Pugazhenthi, S., Nesterova, A., Sable, C., Heidenreich, K. A., Boxer, L. M., Heasley, L. E., et al. (2000). Akt/protein kinase B up-regulates Bcl-2 expression through cAMPresponse element-binding protein. $J$. Biol. Chem. 275, 10761-10766. doi: 10.1074/jbc.275.15.10761

Rainey-Smith, S. R., Andersson, D. A., Williams, R. J., and Rattray, M. (2010). Tumour necrosis factor alpha induces rapid reduction in AMPA receptor-mediated calcium entry in motor neurones by increasing cell surface expression of the GluR2 subunit: relevance to neurodegeneration. J. Neurochem. 113, 692 703. doi: $10.1111 / j .1471-4159.2010$. 06634.x

Raoul, C., Estevez, A. G., Nishimune, H., Cleveland, D. W., Delapeyriere, O., Henderson, C. E., et al. (2002). Motoneuron death triggered by a specific pathway downstream of Fas. Potentiation by ALS-linked SOD1 mutations. Neuron 35, 1067 1083. doi: 10.1016/S0896-6273(02) 00905-4

Rosenstein, J. M., Krum, J. M., and Ruhrberg, C. (2012). VEGF in the nervous system. Organogenesis 6, 107-114. doi: 10.4161/org.6.2. 11687

Rothstein, J. D. (2009). Current hypotheses for the underlying biology of amyotrophic lateral sclerosis. Ann. Neurol. 65(Suppl. 1), S3-S9. doi: 10.1002/ana.21543

Ruiz de Almodovar, C., Coulon, C., Salin, P. A., Knevels, E., Chounlamountri, N., Poesen, K., et al. (2010). Matrix-binding vascular endothelial growth factor (VEGF) isoforms guide granule cell migration in the cerebellum via VEGF receptor Flk1. J. Neurosci. 30, 15052-15066. doi: 10.1523/JNEUROSCI.0477-10 2010

Ruiz de Almodovar, C., Fabre, P. J., Knevels, E., Coulon, C., Segura, I., Haddick, P. C., et al. (2011). VEGF mediates commissural axon chemoattraction through its receptor Flk1. Neuron 70, 966978. doi: 10.1016/j.neuron.2011.04 014

Ruiz de Almodovar, C., Lambrechts, D., Mazzone, M., and Carmeliet, P. (2009). Role and therapeutic potential of VEGF in the nervous system. Physiol. Rev. 89, 607648. doi: 10.1152/physrev.00031. 2008
Ryu, J. K., Cho, T., Choi, H. B., Wang, Y. T., and Mclarnon, J. G. (2009). Microglial VEGF receptor response is an integral chemotactic component in Alzheimer's disease pathology. J. Neurosci. 29, 3-13. doi: 10.1523/JNEUROSCI.2888-08. 2009

Sargsyan, S. A., Monk, P. N., and Shaw, P. J. (2005). Microglia as potential contributors to motor neuron injury in amyotrophic lateral sclerosis. Glia 51, 241-253. doi: 10.1002/glia. 20210

Sathasivam, S. (2008). VEGF and ALS. Neurosci. Res. 62, 71-77. doi: 10.1016/j.neures.2008.06.008

Schiera, G., Proia, P., Alberti, C., Mineo, M., Savettieri, G., and Di Liegro, I. (2007). Neurons produce FGF2 and VEGF and secrete them at least in part by shedding extracellular vesicles. J. Cell. Mol. Med. 11, 1384 1394. doi: 10.1111/j.1582-4934.2007. 00100.x

Schwarz, Q., Gu, C., Fujisawa, H., Sabelko, K., Gertsenstein, M., Nagy, A., et al. (2004). Vascular endothelial growth factor controls neuronal migration and cooperates with Sema3A to pattern distinct compartments of the facial nerve. Genes Dev. 18, 2822-2834. doi: 10.1101/gad.322904

Semenova, M. M., Maki-Hokkonen, A. M., Cao, J., Komarovski, V., Forsberg, K. M., Koistinaho, M., et al. (2007). Rho mediates calciumdependent activation of p38alpha and subsequent excitotoxic cell death. Nat. Neurosci. 10, 436-443.

Sondell, M., Lundborg, G., and Kanje, M. (1999). Vascular endothelial growth factor has neurotrophic activity and stimulates axonal outgrowth, enhancing cell survival and Schwann cell proliferation in the peripheral nervous system. J. Neurosci. 19, 5731-5740.

Sondell, M., Sundler, F., and Kanje, M. (2000). Vascular endothelial growth factor is a neurotrophic factor which stimulates axonal outgrowth through the flk-1 receptor. Eur. J. Neurosci. 12, 4243-4254. doi: 10.1046/j.0953816X.2000.01326.x

Storkebaum, E., Lambrechts, D., Dewerchin, M., Moreno-Murciano, M. P., Appelmans, S., Oh, H., et al. (2005). Treatment of motoneuron degeneration by intracerebroventricular delivery of VEGF in a rat model of ALS. Nat. Neurosci. 8, 85-92. doi: 10.1038/nn1360

Sun, H., Kawahara, Y., Ito, K., Kanazawa, I., and Kwak, S. (2006). Slow and selective death of spinal motor neurons in vivo by intrathecal infusion of kainic acid: implications for AMPA receptor-mediated excitotoxicity in ALS. J. Neurochem. 98, 782791. doi: 10.1111/j.1471-4159.2006. 03903.x

Takahashi, H., and Shibuya, M. (2005). The vascular endothelial growth factor (VEGF)/VEGF receptor system and its role under physiological and pathological conditions. Clin. Sci. (Lond.) 109, 227-241. doi: 10.1042/CS20040370

Tolosa, L., Mir, M., Asensio, V. J., Olmos, G., and Llado, J. (2008). Vascular endothelial growth factor protects spinal cord motoneurons against glutamate-induced excitotoxicity via phosphatidylinositol 3-kinase. J. Neurochem. 105, 1080-1090. doi: 10.1111/j.1471-4159.2007.05206.x

Tolosa, L., Mir, M., Olmos, G., and Llado, J. (2009). Vascular endothelial growth factor protects motoneurons from serum deprivation-induced cell death through phosphatidylinositol 3-kinase-mediated p38 mitogenactivated protein kinase inhibition. Neuroscience 158, 1348-1355. doi: $\quad 10.1016 /$ j.neuroscience. 2008 10.060

Tortarolo, M., Veglianese, P., Calvaresi, N., Botturi, A., Rossi, C., Giorgini, A., et al. (2003). Persistent activation of p38 mitogenactivated protein kinase in a mouse model of familial amyotrophic lateral sclerosis correlates with disease progression. Mol. Cell. Neurosci. 23, 180 192. doi: 10.1016/S1044-7431(03) 00022-8

Tovar-Y-Romo, L. B., and Tapia, R. (2010). VEGF protects spinal motor neurons against chronic excitotoxic degeneration in vivo by activation of PI3-K pathway and inhibition of p38MAPK. J. Neurochem. 115, 1090-1101. doi: 10.1111/j.14714159.2010.06766.x

Tovar-y-Romo, L. B., and Tapia, R. (2012). Delayed administration of VEGF rescues spinal motor neurons from death with a short effective time frame in excitotoxic experimental models in vivo. ASN Neuro 4, e00081. doi: 10.1042/AN2011 0057

Tovar-Y-Romo, L. B., Zepeda, A., and Tapia, R. (2007). Vascular endothelial growth factor prevents paralysis and motoneuron death in a rat model of excitotoxic spinal cord neurodegeneration. J. Neuropathol. Exp. Neurol. 66, 913 922. doi: 10.1097/nen.0b013e31815 $67 \mathrm{c} 16$

Van Damme, P., Bogaert, E., Dewil, M., Hersmus, N., Kiraly, D., Scheveneels,
W., et al. (2007). Astrocytes regulate GluR2 expression in motor neurons and their vulnerability to excitotoxicity. Proc. Natl. Acad. Sci. U.S.A. 104, 14825-14830. doi: 10.1073/pnas.0705046104

Van Damme, P., Van Den Bosch, L., Van Houtte, E., Callewaert, G., and Robberecht, W. (2002). GluR2dependent properties of AMPA receptors determine the selective vulnerability of motor neurons to excitotoxicity. J. Neurophysiol. 88, 12791287.

Van Den Bosch, L., Storkebaum, E., Vleminckx, V., Moons, L., Vanopdenbosch, L., Scheveneels, W., etal. (2004). Effects of vascular endothelial growth factor (VEGF) on motor neuron degeneration. Neurobiol. Dis. 17, 21-28. doi: 10.1016/j.nbd.2004.06.004

Van Den Bosch, L., Van Damme, P., Bogaert, E., and Robberecht, W. (2006). The role of excitotoxicity in the pathogenesis of amyotrophic lateral sclerosis. Biochim. Biophys. Acta 1762, 1068-1082. doi: 10.1016/j.bbadis.2006.05.002

Van Den Bosch, L., Vandenberghe, W., Klaassen, H., Van Houtte, E., and Robberecht, W. (2000). $\mathrm{Ca}(2+)$-permeable AMPA receptors and selective vulnerability of motor neurons. J. Neurol. Sci. 180, 2934. doi: 10.1016/S0022-510X(00) 00414-7

Wang, Y., Mao, X. O., Xie, L., Banwait, S., Marti, H. H., Greenberg, D. A., et al. (2007). Vascular endothelial growth factor overexpression delays neurodegeneration and prolongs survival in amyotrophic lateral sclerosis mice. J. Neurosci. 27, 304-307. doi: 10.1523/JNEUROSCI.4433-06. 2007

Young, P. P., Fantz, C. R., and Sands, M. S. (2004). VEGF disrupts the neonatal blood-brain barrier and increases life span after nonablative BMT in a murine model of congenital neurodegeneration caused by a lysosomal enzyme deficiency. Exp. Neurol. 188, 104-114. doi: 10.1016/j.expneurol.2004.03. 007

Zheng, C., Skold, M. K., Li, J., Nennesmo, I., Fadeel, B., and Henter, J. I. (2007). VEGF reduces astrogliosis and preserves neuromuscular junctions in ALS transgenic mice. Biochem. Biophys. Res. Commun. 363, 989993. doi: 10.1016/j.bbrc.2007.09. Y088

Zhong, L. T., Kane, D. J., and Bredesen, D. E. (1993). BCL-2 blocks glutamate toxicity in neural cell lines. Brain Res. 
Mol. Brain Res. 19, 353-355. doi: 10.1016/0169-328X(93)90139-G

Conflict of Interest Statement: The authors declare that the research was conducted in the absence of any commercial or financial relationships that could be construed as a potential conflict of interest.
Received: 31 July 2013; paper pending published: 26 August 2013; accepted: 30 September 2013; published online: 21 October 2013.

Citation: Lladó J, Tolosa L and Olmos $G$ (2013) Cellular and molecular mechanisms involved in the neuroprotective effects of VEGF on motoneurons. Front.
Cell. Neurosci. 7:181. doi: 10.3389/fncel. 2013.00181

This article was submitted to the journal Frontiers in Cellular Neuroscience.

Copyright (c) 2013 Lladó, Tolosa and Olmos. This is an open-access article distributed under the terms of the Creative Commons Attribution License (CC BY).
The use, distribution or reproduction in other forums is permitted, provided the original author(s) or licensor are credited and that the original publication in this journal is cited, in accordance with accepted academic practice. No use, distribution or reproduction is permitted which does not comply with these terms. 